\title{
Comparative examination of scale-explicit biological and physical processes: recruitment of Pacific hake (Merluccius productus)
}

\author{
J ohn K. Horne, Paul E. Smith, and David C. Schneider
}

\begin{abstract}
The creation, maintenance, and destruction of aquatic organism distributions result from biological and physical processes that operate at different spatial and temporal scales. Rate diagrams plot and contour ratios of process rates as a function of spatial and temporal scale to summarize the relative importance of demographics, growth, and kinematics. We demonstrate the utility of this approach by examining physical and biological processes that influence the distribution and survival of larval and juvenile Pacific hake (Merluccius productus) in the California Current region. Processes that influence changes in hake biomass switch from mortality and drift among larvae to somatic growth and active locomotion among juveniles. Comparison of hake rate diagrams with those of capelin (Mallotus villosus) and Atlantic cod (Gadus morhua) show that dominant processes differ across scales, across life history stages, and across species.
\end{abstract}

Résumé : La création, le maintien et la disparition des aires de répartition des organismes aquatiques résultent de processus biologiques et physiques qui agissent à des échelles spatiales et temporelles différentes. Des diagrammes de taux et des rapports d'isolignes des taux des processus en fonction de l'échelle spatiale et temporelle sont présentés pour résumer l'importance relative des facteurs liés à la démographie, à la croissance et à la cinématique. Nous démontrons l'utilité de cette approche de par un examen des processus physiques et biologiques qui influent sur la répartition et la survie des larves et des juvéniles du merlu du Pacifique (Merluccius productus) dans la région du courant de Californie. Les processus qui influent sur la variation de la biomasse du merlu vont de la mortalité et de la dérive chez les larves à la croissance somatique et au déplacement actif chez les juvéniles. La comparaison des diagrammes du merlu avec ceux du capelan (Mallotus villosus) et de la morue franche (Gadus morhua) montre que les processus dominants varient selon l'échelle, l'étape du cycle vital et l'espèce.

[Traduit par la Rédaction]

\section{Introduction}

An ongoing challenge to aquatic scientists is applying results from process-oriented investigations to ecosystem conservation and management. Successful ecosystem management depends, in part, on scaling local results to regional or global scales. Unfortunately, direct extrapolation of results across scales is not always possible (Dayton and Tegner 1984; Carpenter et al. 1995; Thrush et al. 1997). "Scaling up" is particularly relevant to the design of aquatic studies where shiptime is limited and geographical areas of interest are extensive. One germane example is identifying the influence of biological and physical processes on the distribution, survival, and eventual recruitment of larval fish co-

Received December 18, 1997. Accepted July 15, 1999. J14351

J.K. Horne. ${ }^{1}$ Cooperative Institute for Limnology and Ecosystems Research, 2205 Commonwealth Bouelvard, Ann Arbor, MI 48105, U.S.A.

P.E. Smith. Southwest Fisheries Center, National Marine Fisheries Service, 8604 La Jolla Shores Drive, La Jolla, CA 92038, U.S.A.

D.C. Schneider. Ocean Sciences Centre, Memorial University of Newfoundland, St. John's, NF A1C 5S7, Canada.

${ }^{1}$ Author to whom all correspondence should be addressed. e-mail: horne@glerl.noaa.gov horts. Death of a single larva occurs at scales of centimetres and seconds, but the subsequent death of the adult cohort potentially spans thousands of kilometres and many years.

A factor that confounds identification of relevant biological and physical processes influencing biological quantities such as population abundance is the dependence of observed pattern on the scale of observation (e.g., Stommel 1963; Haury et al. 1978). Distributional patterns that are evident at one scale may not be evident when the measurement resolution is altered (e.g., Schneider and Piatt 1986). In aquatic environments, efforts to quantify scale-dependent pattern and process have traditionally focused on populations of particles or organisms that drift with water motion (e.g., Platt and Denman 1975; Powell et al. 1975; Horwood 1978). Parallel examinations of mobile organism distributions are not as common (e.g., Horwood and Cushing 1978) but are increasing in number (e.g., Weber et al. 1986; Schneider 1994a; Horne and Schneider 1997). Explicit treatment of scale is rapidly becoming standard practice (e.g., Giller et al. 1994; Schneider 1994b; Peterson and Parker 1998) when quantifying distribution patterns and the relevance of biological and physical processes.

One approach used to quantify the relative importance of biological and physical processes to distributions of biological quantities such as changes in fish biomass compares ratios of rates. To illustrate through example, Platt (1981) analyzed the relative contributions of phytoplankton growth 
and particle diffusion to the formation of a characteristic phytoplankton patch size using a dimensionless ratio (Bridgman 1922). When values of dimensionless ratios equal 1 , they indicate time and space scales where biological and physical rates are similar in magnitude and processes potentially interact. Schneider et al. (1997) labeled these as "critical" time and space scales. For phytoplankton patches, this is the predicted scale where horizontal diffusion is balanced by phytoplankton production. The application of dimensional analysis to evaluate the relative importance of biological and physical processes can be extended to include demographic (i.e., natality, mortality), growth, and kinematic (i.e., locomotion, drift) terms (e.g., Horne and Schneider 1994; Schneider et al. 1997).

Dimensionless ratios computed in these two examples were based on the few biological and physical rates that can be extracted from the literature. The extent of critical scales was obtained by drawing contour lines using biological knowledge of the organisms of interest. An alternate approach (Schneider et al. 1999) extracts dimensionless rates of biological and physical processes from the literature and then uses extensive computation to calculate ratio values at all possible scales. Collectively, these three studies show that ratio values are not constant over all spatial and temporal scales and that critical scales are not limited to a single spatial and temporal scale. Neither the literature extraction nor the computation methods use extensive data or incorporate variability in biological processes such as natality or agedependent mortality when computing dimensionless ratios.

In this paper, we use an extensive data set with a 45-year biological history to examine how biological and physical processes influence the distribution and survival of larval and juvenile fish. Pacific hake (Merluccius productus) is used as an illustrative example, as the genus is present in all of the world's eastern and some western boundary current regions, it has the largest biomass of any demersal species within its latitudinal range $\left(25-55^{\circ} \mathrm{N}\right)$, and recruitment rates can vary over two orders of magnitude in adjacent years (Hollowed 1992; Dorn et al. 1993). We then compare dimensionless ratio values from hake with those for other fish species derived using literature values or extensive computations.

\section{Forming dimensionless ratios}

Rate diagrams use dimensionless ratios to summarize knowledge of biological and physical processes across spatial and temporal scales. The derivation of ratios used in rate diagrams is detailed in Schneider (1991) and Horne and Schneider (1994). A brief outline will be provided here. There are five steps when generating rate diagrams: (i) state the quantity of interest, (ii) choose an analytic perspective, (iii) write an equation incorporating all potential sources of variability, (iv) calculate dimensionless ratios, and (v) plot and contour ratio values using all available data.

Quantities of interest in this study are concentrations of larval $B_{1}$ and juvenile $B_{\mathrm{j}}$ Pacific hake biomass in the eastern Pacific. Biomass concentration $B$ is defined as the number of organisms $N$ multiplied by the average mass of an individual $M$ per unit volume $V$. We chose a Eulerian or fixed grid perspective to encompass the offshore spawning and nearshore nursery area of hake along the southern coast of California.
Schneider et al. (1997) compared Eulerian with Lagrangian derivation of rates used when forming dimensionless ratios.

Proportional changes in the distribution of aquatic biomass $B_{0}$, in this case larval and juvenile hake biomass, are a net result of the expansion or contraction of the volume occupied $\dot{V}$, the flux $F$ of organisms through boundaries of the volume, the net reproductive rate $r$, and the somatic growth rate $m$ :

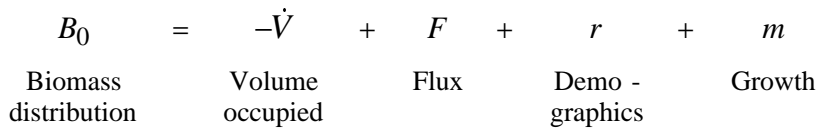

All terms in eq. 1 have units percent per unit time. The two kinematic terms $\dot{V}$ and $F$ can be further partitioned by separating changes in biomass due to passive drift with the surrounding fluid (fl) and from those due to active locomotion (loc):

$$
-\dot{V}+F=-\dot{V}_{\mathrm{fl}}-\dot{V}_{\mathrm{loc}}+F_{\mathrm{fl}}+F_{\mathrm{loc}} .
$$

The demographic term $r$ can be categorized into the per capita birth rate $r_{\mathrm{b}}$ and the per capita death rate $r_{\mathrm{d}}$. If data are available, then the per capita death rate can be further partitioned into natural $r_{\mathrm{n}}$ (e.g., starvation or predation) and harvesting $r_{\mathrm{h}}$ mortality:

$$
r=r_{\mathrm{b}}-r_{\mathrm{d}}=r_{\mathrm{b}}-r_{\mathrm{n}}-r_{\mathrm{h}}
$$

To determine the relative importance of these biological and physical sources of variation, dimensionless ratios (cf. Taylor 1974; Langhaar 1980) were formed using terms in eqs. 1-3. All terms must have the same units, which allows ratios to be formed in any combination relative to a process of interest such as mortality (e.g., Schneider 1992). Alternatively, dimensionless ratios can be formed using functional groups (Fischer et al. 1979) or can be combined in biologically reasonable groups.

The first ratio of interest is changes in biomass due to somatic growth $m$ compared with biomass changes due to population dynamics. The population dynamics label is applied to demographic (i.e., $r$ ) and kinematic (i.e., $\dot{V}$ and $F$ ) terms. Because the range of observation is set to encompass all spawning and brood areas used by hake in the eastern $\mathrm{Pa}-$ cific over the last three decades, there is no change in biomass concentration due to changes in volume occupied. The resulting population dynamics term is a combination of net recruitment $r$ and flux $F$ of individuals in or out of the population:

$$
\frac{m}{r+F}
$$

The second ratio evaluates the relative importance of population dynamics terms by comparing changes in biomass due to demographic $r$ and kinematic $F$ terms:

$$
\frac{r}{F}
$$

A demographic ratio compares changes in biomass due to recruitment with those due to mortality: 


$$
\frac{r_{\mathrm{b}}}{r_{\mathrm{d}}}
$$

Because the quantities of interest are larval and juvenile hake biomass, sources of mortality will not be partitioned to natural and harvesting mortality in this study. The fourth dimensionless ratio examines the relative importance of kinematic terms. Flux in biomass due to organism locomotion is compared with that due to passive drift with the fluid:

$$
\frac{F_{\text {loc }}}{F_{\mathrm{fl}}} .
$$

\section{Methods}

Data for estimating mortality and growth rates of larval and juvenile Pacific hake were extracted from the California Cooperative Oceanic Fisheries Investigations (CalCOFI) database from 1951 through 1995 (see Hewitt 1988 for a review of the program). Larval fish surveys were not conducted in 1967-1968, 1970-1971, 1973-1974, 1976-1977, 1979-1980, and 1982-1983. The latitudinal extent of quarterly larval surveys was reduced during 1985-1994.

\section{Hake spawning and movement}

Hake, the most abundant ichthyoplankton species in the eastern Pacific, is commercially valuable and important to the biological oceanography of western North America (Francis 1983; Smith 1995). Adult hake occupy a narrow feeding habitat near the continental shelf break for 6-8 months in an area extending from California in the south to British Columbia in the north (Alverson and Larkins 1969; Francis 1983; Methot and Dorn 1995). Following a southern migration in winter (Alverson and Larkins 1969; Alheit and Pitcher 1995), 95\% of adult hake spawning occurs between December 19 and March 6 in a $300000-\mathrm{km}^{2}$ area offshore of California and the Baja Peninsula (Ahlstrom and Counts 1955; Hollowed 1992; Smith 1995). Embryos and larvae remain offshore for 4-6 months. Juveniles are found on the Californian continental shelf in an ill-defined brood area (Berry and Perkins 1965; Bailey et al. 1986; Woodbury et al. 1995). Most of the interannual per capita recruitment variability occurs during the first 4 months of life (Hollowed 1992), but the relative importance of biological and physical mechanisms influencing recruitment has not been clearly demonstrated. Bailey and Francis (1985) found that recruitment exceeded the average in 11 of 18 warmer than average years (>14.8 ${ }^{\circ} \mathrm{C}$ at the surface) during 1960-1977. Recruitment, indexed by the abundance of 2 -year-old fish, did not exceed the average in all seven of the colder than average years $\left(<14.8^{\circ} \mathrm{C}\right.$ at the surface) during the same period. Previous studies (Smith 1975; Bailey 1980) showed that cold water temperatures coincided with southern and offshore shifts in adult hake spawning locations, but it has not been proven whether the absence of large cohorts born during "cold years" is a direct or indirect result of water temperature.

In this study, we arbitrarily define the spawning and brood areas using the CalCOFI grid system: the southern boundary is set at Punta Eugenia (line 120), the northern boundary at San Francisco (line 60 ), the seaward boundary at station 120 , and the spawning-brood boundary at station 60 (Fig. 1). We apportion the annual adult migration as $50 \%$ of the year (183 days) spent in the northern feeding area, $18 \%$ (66 days) spent in transit to the spawning grounds, $21 \%$ (76 days) resident in the spawning area, and 11\% (40 days) spent in transit to the adult feeding area. All spawning is assumed to occur within the delineated spawning area. Spawning rates per adult female and survival rates of eggs and larvae are also assumed constant. Larvae are defined as fish less than $20 \mathrm{~mm}$ (Smith 1995; Ambrose 1996). We have further assumed that active swimming by adults and passive transport of eggs and larvae with water currents are uniform. We estimate that the linear distance traveled by adults to the spawning area is $1100 \mathrm{~km}$ (cf. Alverson and Larkins 1969; Wilson et al. 1997) and that the rate of progress is $20 \mathrm{~cm} \cdot \mathrm{s}^{-1}$ or nominally 0.4 body length (bl) $\cdot \mathrm{s}^{-1}$ (cf. Alheit and Pitcher 1995). Neither the stimuli to which the adult hake respond while migrating nor the stimuli that cause them to stop and spawn are known. Larvae begin to appear in mid-December and smaller larvae are not readily found after the first week of March (Smith 1995). Northerly movement by adults continues through the feeding season (Dorn 1996).

\section{Hake population models}

Mortality and growth rates used in dimensionless calculations are derived from Lefkovitch stage-based models (Lefkovitch 1965) of hake abundance, survival, and growth in the California Current region (Smith 1995). Nine life history stages were collapsed by summation into embryo, larval, juvenile, and adult stages. The models use rates of adult maternity and mortality, larval mortality and stage duration, and juvenile stage duration. Adult maternity is defined as the number of fertilized eggs that survive one time step (i.e., day) per female adult. We have assumed that mortality is identical throughout the embryonic period, as little is known about survival postfertilization in open water. Adult natural mortality is assumed equal to that used in virtual population methods (Francis 1983). An equilibrium model of the population is fitted by tuning the juvenile mortality rate (Smith 1985, 1995). Juvenile mortality was adjusted using the size-based mortality rate of Peterson and Wroblewski (Peterson and Wroblewski 1984; Butler et al. 1993). Stage mortalities and adult fecundities are considered representative of demographic and somatic growth rates. The demographic output from the model summarizes the production at the beginning of each stage (i.e., natality and growth) and losses during the stage (i.e., mortality). Somatic growth rates for each stage are estimated using the initial weight-at-stage and duration-within-stage from model output (Smith 1995).

Larval hake production and mortality rates across the continental shelf were characterized using a series of exponential regression models fitted to hake catch-at-size data. Data used in the regressions are taken from CalCOFI cruises conducted from 1951 to 1995. Geographic coverage and seasonal sampling intensity have varied over this time span. Stations were grouped into 74-km (40 nautical miles) distance intervals $i$ from shore. Hake larvae were divided into nine length-classes starting at $2.75 \mathrm{~mm}$ and incremented by $2 \mathrm{~mm}$ to a maximum length of $18.75 \mathrm{~mm}$. The mean abundance of hake larvae in each size-class was tabulated for each station interval $i$. The density of larvae was then plotted as a function of size-class for each distance interval. The slope of the resulting $z_{i}$ curve is proportional to the instantaneous mortality $z_{i}$ (percent per day) across size-classes. The intercept of the curve with the ordinate is proportionate to the instantaneous production $\hat{n}_{0}$. The number of larvae $n_{i}$ at any distance interval can then be modeled as a function of instantaneous production $\hat{n}_{0}$ in each interval and mortality $z_{i}$ across size-classes:

$$
n_{i}=\hat{n}_{0_{i}} \mathrm{e}^{-z_{i}}
$$

Instantaneous production and mortality indices were compared across the continental slope by plotting intercepts and slopes for each distance interval.

\section{Rate diagrams}

Rate diagrams provide a framework to evaluate the relative importance of processes that potentially influence the distribution of any biological quantity of interest. In this example, we qualitatively summarize the relative importance of biological and physical processes to changes in larval and juvenile hake biomass as a function of spatial and temporal scale. Where possible, values for each 
Fig. 1. Pacific hake larval and juvenile habitat within the CalCOFI sampling area. The arbitrary spawning area is shaded and extends from San Francisco (line 60) in the north to Punta Eugenia (line 120) in the south. The seaward boundary is set at station 120. The unshaded zone represents the brood area of older larvae and juveniles at the time of recruiting to the coastal slope and shelf habitat. The brood area boundary is set at station 60. See Hewitt (1988) for a summary of the CalCOFI sampling program.

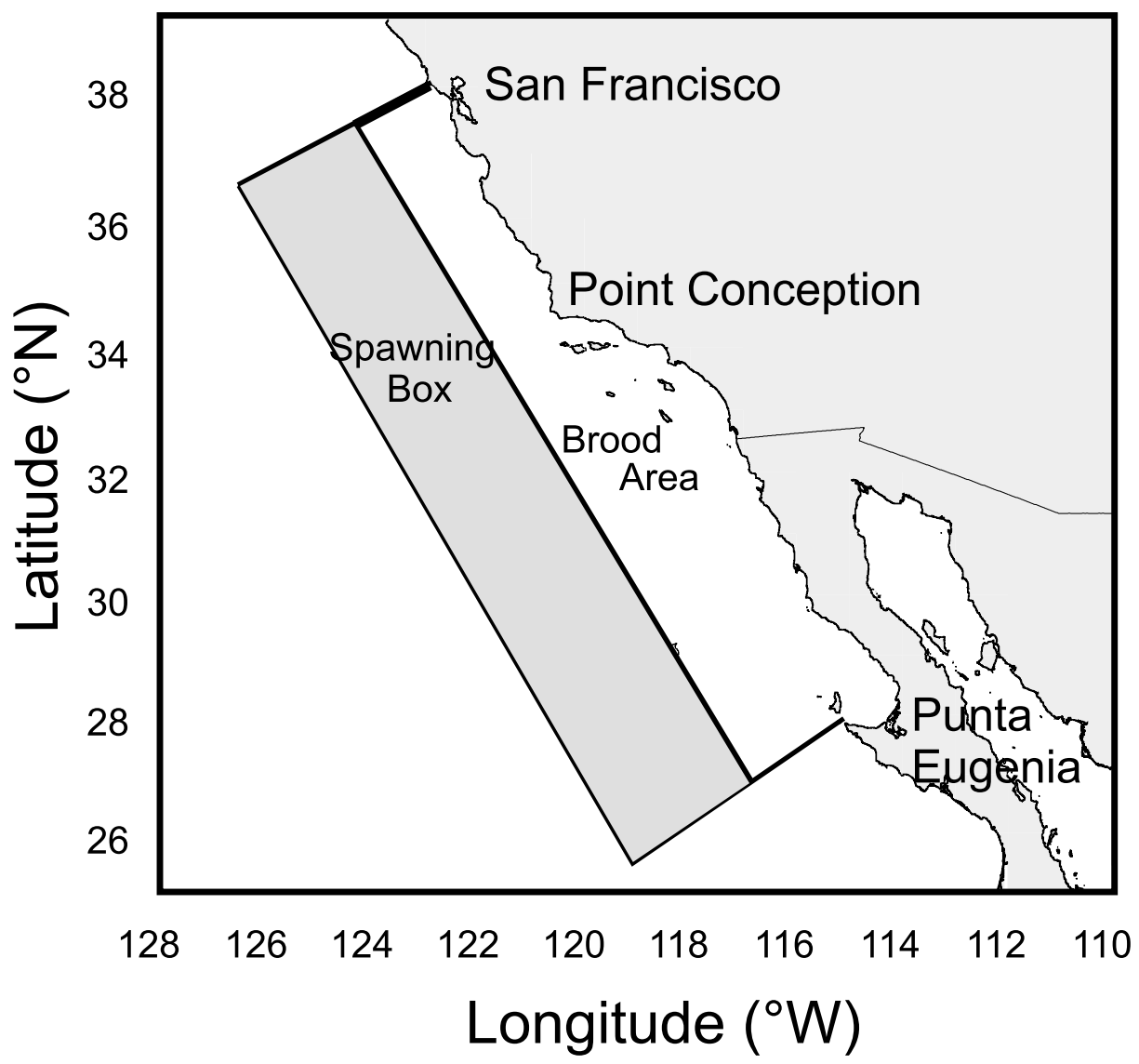

Table 1. Pacific hake life history parameters from the Lefkovitch matrix model.

\begin{tabular}{lclccc}
\hline Stage & Fecundity $\left(\right.$ no. embryos $\cdot$ day $\left.^{-1}\right)$ & Mortality $\left(\right.$ day $\left.^{-1}\right)$ & Duration $($ days $)$ & Initial weight $(\mathrm{g})$ & Length range $(\mathrm{cm})$ \\
\hline Embryo & 0 & 0.135 & 16 & $9.05 \times 10^{-4}$ & Egg-0.4 \\
Larva & 0 & 0.076 & 100 & $3.05 \times 10^{-4}$ & $0.4-2.0$ \\
Juvenile & 0 & 0.0042 & 602 & $1.21 \times 10^{-2}$ & $2.0-33.3$ \\
Adult & 120 & 0.0005 & 6570 & 26.3 & $33.3-62$ \\
\hline
\end{tabular}

ratio were calculated at discrete spatiotemporal scales for larval and juvenile hake using CalCOFI hake data, output from Lefkovitch population models, and velocities of the California Current system. Current vector velocities for the California Current, the California Current Extension, and the Coastal Jet were measured from average annual surface current charts (U.S. Hydrographics Office 1947). Dimensions of all terms in ratios are percent per unit time. Order of magnitude calculations show whether the absolute value of any dimensionless ratio was less than, equal to, or greater than 1 at a specified scale. Nominal values $(>1,=1,<1)$ for each ratio were then plotted as a function of spatial and temporal scale for larval and juvenile hake. Ratio values $>1$ indicate the predominance of processes in the numerator, values $=1$ indicate a potential coupling between processes in the numerator and denominator, and values $<1$ indicate that processes in the denominator dominate over those in the numerator. Contour lines drawn on rate diagrams indicate spatial and temporal scales where dimensionless ratios change value. If data at all scales were not available, ratio values were extended across all scales in the plane. The construction of a rate diagram is an iterative process. Ratio values and con- tour locations should be adjusted as additional data and knowledge become available. No contours were added to hake rate diagrams.

\section{Results}

\section{Matrix growth parameters}

The Lefkovitch matrix model produces growth parameters for embryonic, larval, juvenile, and adult Pacific hake life history stages. The model assumes population stationarity and stable age distributions and that juvenile parameters can be tuned to comply with other life history stages. The CalCOFI database and the Lefkovitch matrix model combine to provide realistic estimates of adult fecundity, instantaneous mortality, stage duration, weight-at-stage, and length range during each stage (Table 1). Fecundity is restricted to the adult life stage. Instantaneous mortality decreases with age, while stage duration, weight, and length all increase with life history stage. Parameter values from the model are 
Fig. 2. Dimensionless ratio values of larval (circles) and juvenile (squares) Pacific hake biomass distribution in the eastern Pacific. (a) Somatic growth to population dynamics (demographics minus kinematic fluxes), $m / r-F$; (b) demographic (natality, mortality) to kinematic fluxes (passive drift, active locomotion), $r / F ;(c)$ demographics, $r_{\mathrm{b}} / r_{\mathrm{d}} ;(d)$ kinematic fluxes, $F_{\text {loc }} / F_{\mathrm{fl}}$. Symbol shading indicates value of dimensionless ratio calculations: open, <1; half solid, $=1$; solid, $>1$.

a

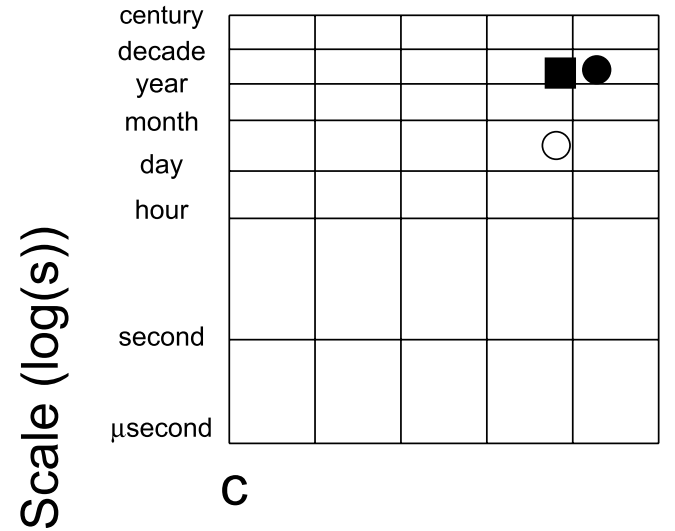

짐

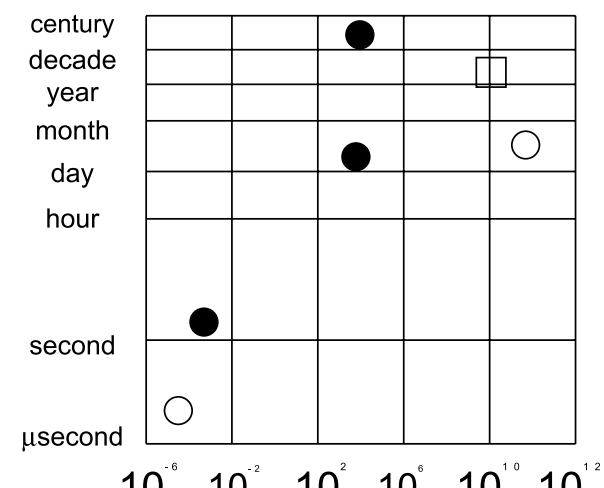

b

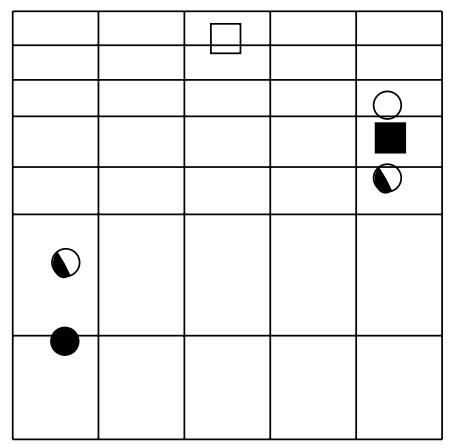

d

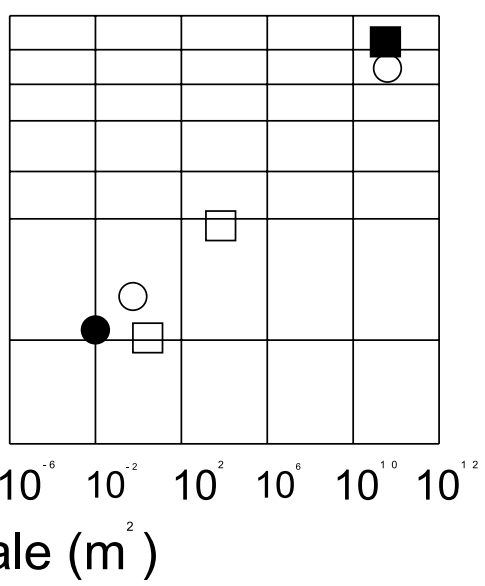

used to compute mortality and somatic growth rates in dimensionless ratios at specific spatial and temporal scales.

\section{Rate diagrams}

The rate diagram of the somatic growth to population dynamics ratio (Fig. 2a) indicates that changes in hake larval biomass concentration due to somatic growth exceed those due to demographic and flux processes at the scale of a spawning season. From the time that eggs are first laid until larvae are transported out of the spawning area, individual fish biomass increases from about $5 \times 10^{-4}$ to $7 \times 10^{-2} \mathrm{~g}$ or $140 \%$ of the birth weight (Smith 1995). Annual recruitment is $100 \%$ of the cohort, and virtually all of the biomass fluxes out of the spawning area. The resulting value of the somatic growth to population dynamics ratio is $>1\left(140 \% \cdot\right.$ season $^{-1} /$ $100 \% \cdot$ season $^{-1}$ ). At daily scales, changes in biomass due to somatic growth are less than those due to demographics and the flux of larvae out of the spawning area and the ratio is $<1\left(1.84 \% \cdot\right.$ day $^{-1} /-13.91 \% \cdot$ day $\left.^{-1}\right)$.

Four values were calculated for the larval demographics to kinematics dimensionless ratio (Fig. 2b). Changes in larval hake biomass due to demographics at temporal scales larger than an annual cycle are balanced by those due to kinematics in the spawning area $\left(100 \% \cdot\right.$ season $^{-1} / 100 \% \cdot$ season $\left.^{-1}\right)$. Over an annual cycle, changes in biomass due to active and pas- sive flux $\left(\approx 100 \% \cdot\right.$ year $\left.^{-1}\right)$ greatly exceed those due to net recruitment $\left(\approx 2.21 \% \cdot\right.$ year $^{-1}$ ) (see below). On a daily basis during an average spawning season of 76 days, the ratio of recruitment to kinematics is approximately equal, as follows. The spawning rate of hake averages $1.3 \%$ of eggs.day ${ }^{-1}$ and larval mortality averages $13 \% \cdot$ day $^{-1}$ (Smith 1995), which results in a net recruitment rate of $1.13 \% \cdot$ day $^{-1}$. Passive flux of larvae from the midline of the spawning box to the eastern boundary $(222 \mathrm{~km})$, based on a net eastern transport by the Coastal Jet $\left(1 \mathrm{~cm} \cdot \mathrm{s}^{-1}\right.$ south) and the California Current ( $4 \mathrm{~cm} \cdot \mathrm{s}^{-1}$ southeast), is $1.48 \% \cdot$ day $^{-1}$. Consequently, the ratio of net recruitment to kinematics will be $1.13 \% \cdot \mathrm{day}^{-1} /$ $1.5 \% \cdot$ day $^{-1}$. If all surviving larvae leave the spawning area, the flux of eggs averaged over the spawning season is $2.21 \%$ of egg production per day out of the spawning area. At the scale of the 76-day spawning season, biomass changes due to egg deposition exceed those due to flux of eggs with water currents.

Persistence of a population requires that biomass changes due to natality and somatic growth must equal or exceed those due to mortality at the largest temporal and spatial scales. Since there is a net flux out of the spawning area, the demographics ratio will exceed a value of 1 (Fig. 2c). At the scale of a spawning season (76 days), natality does not exceed $14 \% \cdot$ week $^{-1}$ and larval mortality is estimated at 
$13 \% \cdot$ day $^{-1}$ (Smith 1995). The resulting value of the demographic ratio is $<1$. At the scale of a spawning event by an aggregation $\left(\approx 10^{6} \mathrm{~m}^{2}\right.$ over a 24 -h cycle) or a spawning pair $\left(\approx 10^{-1} \mathrm{~m}^{2}\right.$, minutes $)$, natality exceeds mortality and the value of the ratio exceeds 1 . Ratio values are $<1$ at spatiotemporal scales of an individual organism dying (square millimetres, seconds).

The rate diagram of the kinematics ratio (Fig. $2 d$ ) indicates the dominance of passive flux over active locomotion across most spatiotemporal scales. Fluxes of larvae due to drift with tides, currents, and upwellings exceed fluxes due to active locomotion except over very short time scales. If an egg is released at the midpoint in the northern half of the spawning area, the net drift is $3.8 \mathrm{~cm} \cdot \mathrm{s}^{-1}$ eastward. About 68 days would elapse for these larvae to drift $222 \mathrm{~km}$ to the boundary of the juvenile brood area. Residence times in the spawning area average 102 days (Smith 1995), so an additional 34 days can be attributed to active locomotion. There is a net $1 \% \cdot$ day $^{-1}$ movement from the midline of the spawning area to the boundary of the juvenile brood area. At the scale of a day, drift of larvae out of the spawning box $\left(3.28 \mathrm{~km} \cdot \mathrm{day}^{-1}\right)$ exceeds that due to average locomotion to remain within the spawning box $\left(1.67 \mathrm{~km} \cdot \mathrm{day}^{-1}\right)$. The resulting value of the ratio $(0.51)$ is $<1$. The kinematic ratio will only exceed a value of 1 at the time and space scale of a larval swimming burst.

In the juvenile hake rate diagrams, the growth to population dynamics ratio (Fig. $2 a$ ) is $>1$ at the scale of the coastal brood area. Changes in biomass due to somatic growth rate (500\% over a 2-year residence period, Smith 1995) exceed those due to changes in recruitment (58\% mortality) and changes due to active flux (100\%) of 2-year-old fish to the adult population. Since growth is a continuous process and juvenile fish remain in the brood area, all other values of the ratio were set at $>1$.

At spatiotemporal scales greater than a brood cycle (about 2 years), the rate diagram of the demographic to flux ratio (Fig. $2 b$ ) indicates that changes in biomass due to the flux of juveniles into and out of the brood area (100\% in 2 years) exceed those due to recruitment ( $58 \%$ mortality by age 2 , Smith 1995). Even if the flux of larvae into the brood area is considered juvenile "natality," changes in biomass due to natality and mortality do not exceed the net flux of biomass out of the brood area. A newly recruited juvenile hake weighs $7 \times 10^{-2} \mathrm{~g}$ when leaving the spawning area and $0.155 \mathrm{~kg}$ at the end of the second year of life (Smith 1995). At temporal scales of a year or less, biomass changes due to juvenile natality $\left(100 \% \cdot\right.$ year $\left.^{-1}\right)$ and mortality $\left(41 \% \cdot\right.$ year $\left.^{-1}\right)$ exceed those due to active ( $41.3 \%$ of age- 2 fish survive and leave) or passive flux $(0 \%)$ out of the brood box. The value of the ratio is $>1\left(59 \% \cdot\right.$ year $^{-1} / 41.3 \% \cdot$ year $\left.^{-1}\right)$.

The demographics rate diagram (Fig. 2c) depicts a ratio $<1$ at the scale of a juvenile brood cycle (i.e., 2 years). Changes in biomass due to mortality over a biannual residence period will exceed those due to natality of juveniles from the spawning area.

The continuous presence of juvenile hake in the brood area over year to decade scales implies that absolute changes in biomass due to active flux exceed those due to drift out of the area with the California Current (Fig. 2d). Episodic events (e.g., upwellings) and large-scale water movements (e.g., currents) can change the value of the ratio to $<1$ over shorter temporal scales throughout the brood area.

The computation of rate diagrams for larval and juvenile hake qualitatively summarizes the relative importance of biological and physical processes influencing survival and distribution of early life history stages. Processes that influence changes in hake biomass switch between the spawning and brood areas at the scale of a spawning season. Changes in larval hake biomass are dominated by mortality and drift with prevailing currents.

\section{Hake survival analyses}

The distribution of larval hake densities across the spawning area illustrates the influence of mortality, growth, and drift on spatial and temporal changes in hake biomass. All catches-at-length from all years sampled during CalCOFI cruises are grouped by length and contoured. Larval fish $(2.75 \mathrm{~mm})$ are concentrated within the spawning area centered at station 5 (about $80 \mathrm{~km}$ offshore) from mid-January to mid February (Fig. 3a). Larvae are also present further offshore of the primary patch at lower concentrations centered at station 10 (about $400 \mathrm{~km}$ offshore) during February. At $6.75 \mathrm{~mm}$ total length the primary patch remains centered on station 5, but densities have dropped by an order of magnitude (Fig. $3 b$ ). Larvae isolated from the primary group are moving further offshore during March along with remnants of the offshore patch. Diffuse concentrations of $12.75-\mathrm{mm}$ hake larvae remain within the spawning area (Fig. 3c). Concentrations of hake are no longer present beyond $200 \mathrm{~km}$ from shore.

Survival of hake larvae is maximized within the spawning box, 200-400 km offshore. Indices of production and mortality are plotted in Fig. 4 at the midpoint of each distance interval. The cross-shelf production index increases with distance offshore, peaking at a distance of $260 \mathrm{~km}$, and then decreasing further seaward. The mortality index is around $-0.91 \mathrm{up}$ to $186 \mathrm{~km}$ offshore and then increases to around -1.04 in distance intervals beyond $260 \mathrm{~km}$.

\section{Discussion}

Rate diagrams enable the relative importance of competing processes to be evaluated at any scale of interest. Rate diagrams are thus useful in identifying relevant sampling scales for process-oriented research. Prior to designing an early life history survey of Pacific hake, it is logical to ask "is drift with currents important to recruitment, and if so, over what scales should the California Current be examined?" From hake life history, we know that the adult spawning season lasts about 76 days each year and occurs offshore from the San Francisco area in the north to Baja, Mexico, in the south. The northern and southern limits of spawning shift among years due to water temperature (Horne and Smith 1997), but suitable spawning "habitat" is assumed to exist along the length of the coast. If we assume that all initial larval movement inshore is net drift with currents, then potential larval transport is $3.87 \mathrm{~cm} \cdot \mathrm{s}^{-1}$ or $3.34 \mathrm{~km} \cdot \mathrm{day}^{-1}$. The spawning box (Fig. 1) covers an area of about $600000 \mathrm{~km}^{2}$. At the spatiotemporal scale of a spawning season, the rate diagram for the ratio of larval growth to population dynamics (Fig. 2a) indicates that demographic 
Fig. 3. Areal density of larval Pacific hake at (a) $2.75 \mathrm{~mm}$, (b) $6.75 \mathrm{~mm}$, and (c) $12.75 \mathrm{~mm}$ total length, contoured as a function of month and distance offshore. All hake catches from all years are used in contour plots. Size-classes are not directly related to age.

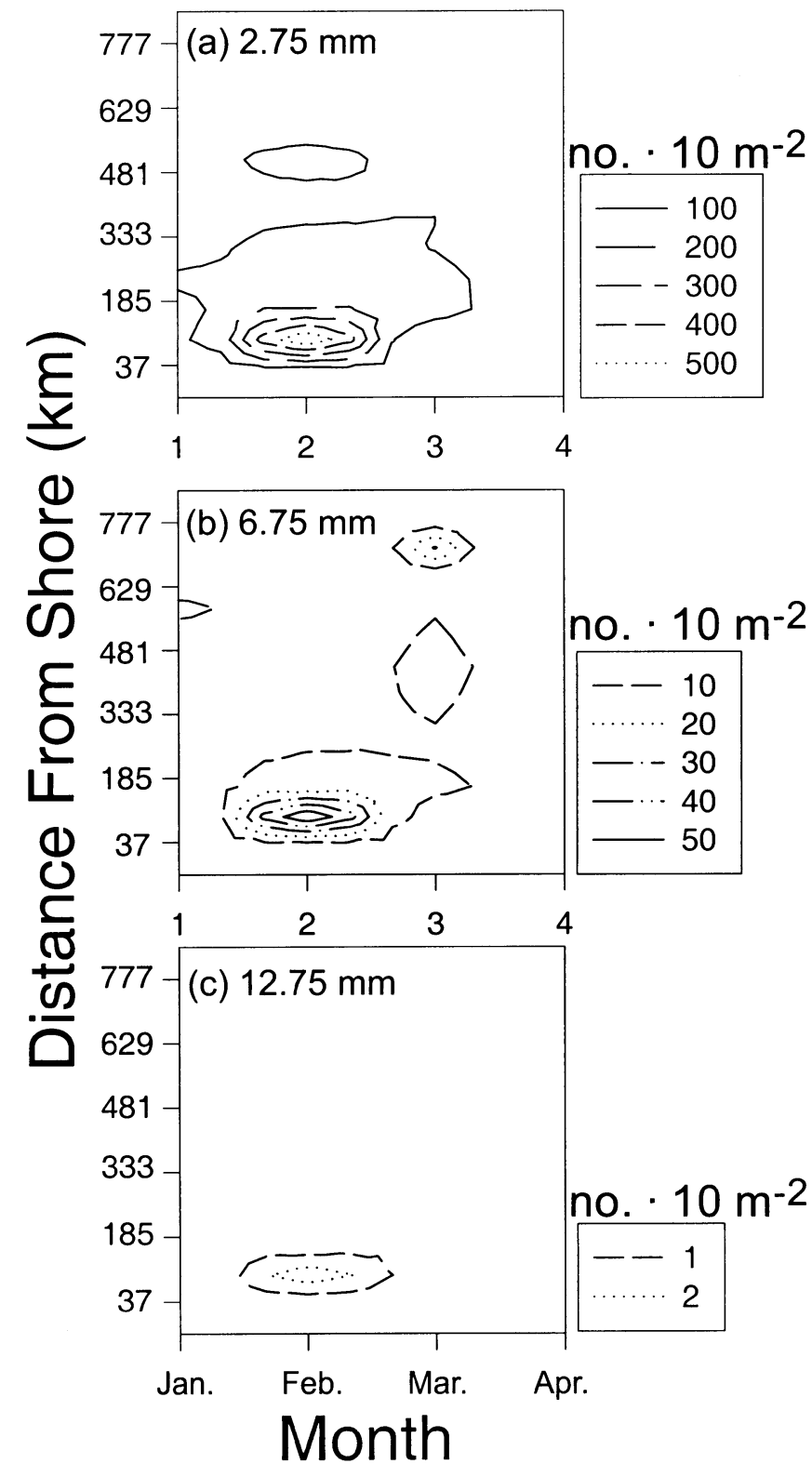

and kinematic processes are more important than growth processes. The ratio of demographic to kinematic rates (Fig. 2b) is $<1$, although at smaller temporal scales, demographic and kinematic processes may be important to the recruitment of hake. Further comparison shows that kinematic processes are dominated by flux out of the spawning area (Fig. $2 d$ ) and that mortality exceeds changes in biomass due to natality (Fig. 2c). When the focus is shifted to juvenile hake, changes in biomass due to somatic growth exceed those due to drift with currents (Fig. 2a). Over the course of a spawning season, larval research effort should focus on drift and mortality at a scale of days to months and kilometres.

The anticipated importance of drift and mortality to larval
Fig. 4. Production and mortality indices of catch-at-length curves for 74-km distance intervals offshore within the CalCOFI sampling grid. Slopes are proportional to instantaneous mortality rates estimated using an exponential model. Intercepts of the exponential curve with the ordinate are proportional to instantaneous production.

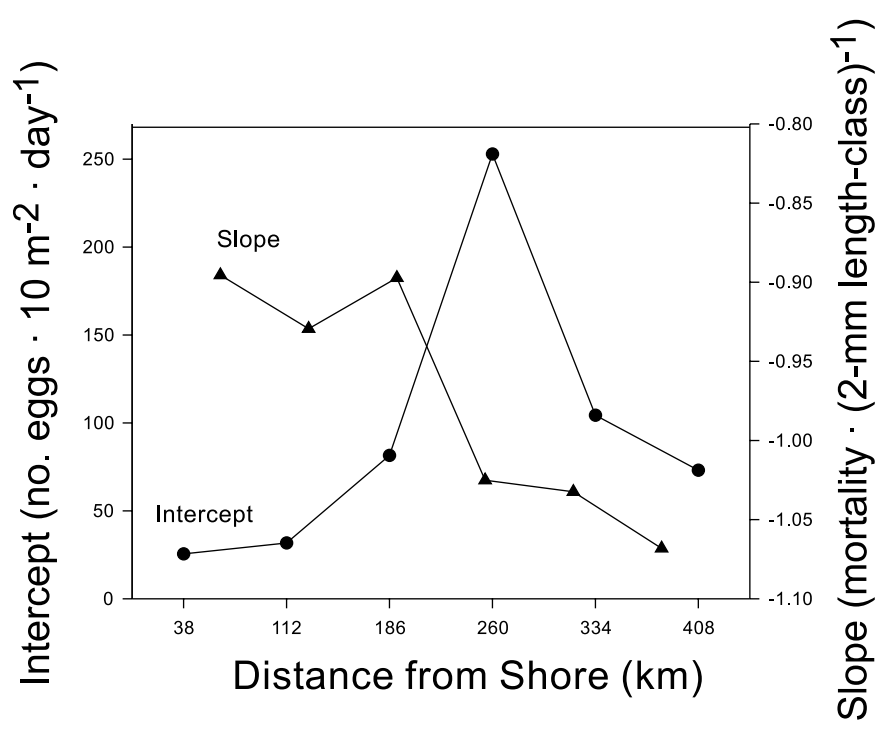

hake survival (Fig. 2) was then examined by drawing contour plots of larval density (Fig. 3) and then plotting production and mortality indices as a function of distance from shore (Fig. 4). Larval hake that are spawned or drift offshore survive through March at $6.75 \mathrm{~mm}$ but are not present in larger length-classes. Increased survival of larval hake is associated with high spawn production. A plateau in larval hake instantaneous mortality occurs just inshore of the peak in hake production. This result suggests inshore transport of surviving older hake larvae and indicates a potential offshore limit for increased hake survival. The coincidence of increased production and decreased mortality in hake starkly contrasts with patterns observed in two co-occurring fish species with coincident spawning and brood areas: northern anchovy (Engraulis mordax) and Pacific sardine (Sardinops sagax). Anchovy and sardine spawn is concentrated well inshore of hake production, and mortality generally increases with distance from shore (see fig. 7 in Smith et al. 2000). Despite differences in peak adult spawning location, critical spatial and temporal scales for passive kinematics (i.e., drift) and mortality are similar among these three co-occurring species.

Rate diagrams for larval and juvenile hake share some features included in rate diagrams for capelin (Mallotus villosus) (Horne and Schneider 1994) and Atlantic cod (Gadus morhua) (Schneider et al. 1999). The "critical scale" envelope observed in the larval hake rate diagram is not identical to that in juveniles. The critical scale envelope observed in mortality to movement rate diagrams for all life history stages of cod was also present in the larval and juvenile hake demographic to kinematic rate diagrams. A comparable envelope may exist in the capelin demographics to kinematic rate diagram (cf. fig. $1 b$ in Horne and Schneider 1994), although the data are too sparse to be certain. It is worth noting that computation of ratios used in rate dia- 
grams for capelin (Horne and Schneider 1994), cod (Schneider et al. this volume), and hake differs in the amount of data used to calculate dimensionless rates. Capelin rate diagrams were based on published literature values, which were few in number. Cod rate diagrams were based again on published values from the literature, augmented by extensive computation based on rough estimates of movement rates. Hake diagrams were based on extensive and relatively detailed spatial data from the CalCOFI program, augmented by computations from a population model that has been verified against survey data. A critical scale envelope (Schneider et al. 1999) is consistent with the results of capelin and hake diagrams, but further applications are needed to test the generality of these envelopes.

The approach used to identify important processes that generate spatial variance in fish density differs from the approach used to identify characteristic phytoplankton patch scales. The application of classical dimensional analysis (Bridgman 1922) to the analysis of phytoplankton patches balances the dissipating force of horizontal diffusion with the concentrating force of phytoplankton reproductive rates. The two processes converge at a critical scale where cell production equals export because of the reduction in patch perimeter relative to patch area (Skellam 1951; Kierstead and Slobodkin 1953). This approach assumes that discrete patches exist, and the objective was to determine the critical patch size. But discrete patches do not persist in the ocean, and mixing will import as well as export phytoplankton from a patch. In contrast, the approach used to evaluate biological and physical processes influencing changes in fish distribution and critical scales nests small compartments within larger compartments and can be termed "coarse graining." With this method, the resolution of measurement is arbitrarily set and multiscale analysis is accomplished by examining the ratio of two rates at multiple resolutions. The analytic procedure is analogous to removing walls of contiguous compartments to create larger compartments within the same area, so that the distance over which averages are computed increases. Coarse graining examines how the dynamics of a quantity of interest change over a continuous range of measurement resolution scales. It is interesting to note that a single critical scale is obtained when just two values are used to compare rates (as in the classical work on critical patch size). More complex dynamics emerge when values reported at several scales are combined, whether by drawing contour lines by hand (Horne and Schneider 1994; Schneider et al. 1997) or by coarse graining (Schneider et al. 1999).

It is not yet clear whether an Eulerian (i.e., fixed) perspective or a Lagrangian (i.e., moving) perspective is more appropriate for examining the relative importance of competing rates. The hake and cod studies in this volume use an Eulerian perspective, in contrast with earlier Lagrangian studies (Schneider 1991, 1993; Horne and Schneider 1994; Schneider et al. 1997). These Lagrangian formulations omitted a kinematic term, the expansion and contraction of the boundaries drawn around finite areas (Schneider et al. 1997). Computation of this kinematic term would require enough information on the location of marked individuals or groups to be able to plot and then measure boundaries at several points in time. This is rarely possible for marine organisms, and hence, the Lagrangian approach requires the assumption that boundaries drawn around finite areas do not expand and contract to a great degree.

Rate diagrams make explicit the relative importance of concomitant processes, which act to generate, maintain, or reduce spatial variance in population density. Rate diagrams constructed to date make it evident that there is no single critical scale at which one rate prevails over another. Instead, populations of marine organisms exhibit more complex dynamics, where the relative importance of concomitant process will vary, depending on spatial and temporal scale. The multiscale approach differs from more traditional approaches to population dynamics of exploited species, for which surveys and assessments are carried out at a single spatial scale (that of the stock) and a single temporal resolution (typically an annual survey). Our results, for the analysis of hake, show that it is possible to combine multiscale analysis with traditional methods for analyzing exploited species. Rate diagrams (Fig. 2), with their capacity to reveal complex dynamics at multiple scales, proved useful in guiding analysis of the spatial dynamics of hake (Figs. 3 and 4). Better integration of multiscale analysis with traditional population analysis remains, however, a major challenge.

\section{Acknowledgments}

This work was supported in part by the National Science Foundation (OCE-9415740 to S.B. Brandt), the New York Sea Grant Institute (NA46RG0090 to S.B. Brandt, J.K.H., J. Tyler, and G. Sprules), the Fisheries Society of the British Isles (travel grant to J.K.H.), and the Natural Sciences and Engineering Research Council of Canada (fellowship support to J.K.H. and long-term research funding to D.C.S.). We thank Drs. R.A. Neal, S.B. Brandt, and two anonymous reviewers for comments that improved the manuscript. This is GLERL contribution No. 1134.

\section{References}

Ahlstrom, E.H., and Counts, R.C. 1955. Eggs and larvae of the Pacific hake, Merluccius productus. Fish Bull. U.S. 56: 295-329.

Alheit, J., and Pitcher, T.J. 1995. Hake: biology, fisheries and markets. Chapman and Hall, London, U.K.

Alverson, D.L., and Larkins, H.A. 1969. Status of the knowledge of the Pacific hake resource. Calif. Coop. Oceanic Fish. Invest. Rep. 13: 24-31.

Ambrose, D.A. 1996. Merlucciidae: hakes. In The early stages of fishes in the California Current region. Edited by H.G. Moser. Calif. Coop. Oceanic Fish. Invest. Atlas, 33: 508-509.

Bailey, K.M. 1980. Recent changes in the distribution of hake larvae: causes and consequences. Calif. Coop. Oceanic Fish. Invest. Rep. 21: 167-171.

Bailey, K.M., and Francis, R.C. 1985. Recruitment of Pacific whiting, Merluccius productus, and the ocean environment. Mar. Fish. Rev. 47: 8-15.

Bailey, K.M., Francis, R.C., and Mais, K.F. 1986. Evaluating incidental catches of 0 -age Pacific hake to forecast recruitment. Calif. Coop. Oceanic Fish. Invest. Rep. 27: 109-112.

Berry, F.H., and Perkins, H.C. 1965. Survey of pelagic fishes of the California Current area. Fish. Bull. U.S. 65: 625-682.

Bridgman, P.W. 1922. Dimensional analysis. Yale University Press, New Haven, Conn.

Butler, J.L., Smith, P.E., and Lo, N.C.H. 1993. The effect of natural variability of life-history parameters on anchovy and sardine 
population growth. Calif. Coop. Oceanic Fish. Invest. Rep. 3: 104-111.

Carpenter, S.J., Chisholm, S.W., Krebs, C.J., Schindler, D.W., and Wright, R.F. 1995. Ecosystem experiments. Science (Washington, D.C.), 269: 324-327.

Dayton, P.K., and Tegner, M.J. 1984. The importance of scale in community ecology: a kelp forest example with terrestrial analogs. In A new ecology: novel approaches to interactive systems. Edited by P.W. Price, C.N. Slobodchikof, and C.N. Gaud. Wiley, New York. pp. 457-481.

Dorn, M.W. 1996. Status of the coastal Pacific whiting resource in 1995. In Pacific Fishery Management Council, status of the Pacific groundfish fishery through 1995 and recommended acceptable biological catches in 1996. Pacific Fishery Management Council, Metro Center, Suite 420, 2000 SW First Ave, Portland, OR 97201, U.S.A. pp. A1-A52.

Dorn, M.W., Nunnallee, E.P., Wilson, C.D., and Wilkins, M.E. 1993. Status of the coastal Pacific whiting resource in 1993. NOAA Tech. Memo. F/AFSC-47.

Fischer, H., List, E.J., Koh, R.C.Y., Imberger, J., and Brooks, N.H. 1979. Dimensional analysis. In Mixing in inland and coastal waters. Academic Press, New York. pp. 23-29.

Francis, R.C. 1983. Population and trophic dynamics of Pacific hake (Merluccius productus). Can. J. Fish. Aquat. Sci. 40: 1925-1943.

Giller, P.S., Hildrew, A.G., and Rafaelli, E. (Editors). 1994. Aquatic ecology: scale, pattern and process. Blackwell, Oxford, U.K.

Haury, L.R., McGowan, J.A., and Wiebe, P.H. 1978. Patterns and processes in the time-space scales of plankton distributions. In Spatial pattern in plankton communities. Edited by J.H. Steele. Plenum Press, New York. pp. 277-327.

Hewitt, R.P. 1988. Historical review of the oceanographic approach to fishery research. Calif. Coop. Oceanic Fish. Invest. Rep. 29: 27-41.

Hollowed, A.B. 1992. Spatial and temporal distribution of Pacific hake larvae Merluccius productus, and estimates of survival during early life stages. Calif. Coop. Oceanic Fish. Invest. Rep. 33: $100-123$.

Horne, J.K., and Schneider, D.C. 1994. Analysis of scale-dependent processes with dimensionless ratios. Oikos, 70: 201-211.

Horne, J.K., and Schneider, D.C. 1997. Spatial variance of mobile aquatic organisms: capelin and cod in Newfoundland coastal waters. Philos. Trans. R. Soc. Lond. B. Biol. Sci. 352: 633-642.

Horne, J.K., and Smith, P.E. 1997. Space and time scales in Pacific hake recruitment processes: latitudinal variation over annual cycles. Calif. Coop. Oceanic Fish. Invest. Rep. 38: 90-102.

Horwood, J.W. 1978. Observations on spatial heterogeneity of surface chlorophyll in one and two dimensions. J. Mar. Biol. Assoc. U.K. 58: $487-502$.

Horwood, J.W., and Cushing, D.H. 1978. Spatial distributions and ecology of pelagic fish. In Spatial pattern in plankton communities. Edited by J.H. Steele. Plenum Press, New York. pp. 355-382.

Kierstead, H., and Slobodkin, L.B. 1953.The size of water masses containing plankton blooms. J. Mar. Res. 12: 141-147.

Langhaar, H.L. 1980. Dimensional analysis and the theory of models. Krieger Publishing, Huntington, N.Y.

Lefkovitch, L.P. 1965. The study of population growth in organisms grouped by stages. Biometrics, 21: 1-18.

Methot, R.D., and Dorn, M.W. 1995. Biology and fisheries of north Pacific hake (M. productus). In Hake: biology, fisheries and markets. Edited by J. Alheit and T.J. Pitcher. Chapman and Hall, London, U.K. pp. 389-414.

Peterson, D., and Parker, T. (Editors). 1998. Scale issues in ecology. Columbia University Press, New York.
Peterson, I., and Wroblewski, J.S. 1984. Mortality rate of fishes in the pelagic ecosystem. Can. J. Fish. Aquat. Sci. 41: 1117-1120.

Platt, T. 1981. Thinking in terms of scale: introduction to dimensional analysis. In Mathematical models in biological oceanography. Edited by T. Platt, K.H. Mann, and R.E. Ulanowicz. UNESCO Press, Paris. pp. 112-121.

Platt, T., and Denman, K.L. 1975. Spectral analysis in ecology. Annu. Rev. Ecol. Syst. 6: 189-210.

Powell, T.M., Richerson, P.J., Dillon, T.M., Agee, B.A., Dozier, B.J., Godden, D.A., and Myrup, L.O. 1975. Spatial scales of current speed and phytoplankton biomass fluctuations in Lake Tahoe. Science (Washington, D.C.), 189: 1088-1090.

Schneider, D.C. 1991. The role of fluid dynamics in the ecology of marine birds. Oceanogr. Mar. Biol. Annu. Rev. 29: 487-521.

Schneider, D.C. 1992. Thinning and clearing of prey by predators. Am. Nat. 139: 148-160.

Schneider, D.C. 1993. Scale-dependent spatial dynamics: marine birds in the Bering Sea. Biol. Rev. Camb. Philos. Soc. 68: 579-598.

Schneider, D.C. 1994a. Scale-dependent patterns and species interactions in marine nekton. In aquatic ecology: scale, pattern and process. Edited by P.S. Giller, A.G. Hildrew, and E. Rafaelli. Blackwell, Oxford, U.K. pp. 441-467.

Schneider, D.C. 1994b. Quantitative ecology. Academic Press, San Diego, Calif.

Schneider, D.C., and Piatt, J.F. 1986. Scale-dependent correlation of seabirds with schooling fish in a coastal ecosystem. Mar. Ecol. Prog. Ser. 32: 237-246.

Schneider, D.C., Walters, R., Thrush, S., and Dayton, P. 1997. Scale-up of ecological experiments: density variation in the mobile bivalve Macomona liliana. J. Exp. Mar. Biol. Ecol. 216: 129-152.

Schneider, D.C., Bult, T., Gregory, R.S., Methven, D.A., Ings, D.W., and Gotceitas, V. 1999. Mortality, movement, and body size: critical scales for Atlantic cod (Gadus morhua) in the Northwest Atlantic. Can. J. Fish. Aquat. Sci. 56(Suppl. 1). This issue.

Skellam, J.G. 1951. Random dispersal in theoretical populations. Biometrika, 78: 196-218.

Smith, P.E. 1975. Pacific hake larval distribution and abundance. SWFC Admin. Rep. LJ-75-83. Southwest Fisheries Center, National Marine Fisheries Service, La Jolla, Calif.

Smith, P.E. 1985. Year-class strength and survival of 0-group clupeoids. Can. J. Fish. Aquat. Sci. 42(Suppl. 1): 69-82.

Smith, P.E. 1995. Development of the population biology of the Pacific hake, Merluccius productus. Calif. Coop. Oceanic Fish. Invest. Rep. 36: 144-152.

Smith, P.E., Horne, J.K., and Schneider, D.C. 2000. Life history strategies of anchovy, sardine and hake in the California Current: comparison of spatial dynamics of the pre-recruit stages. ICES J. Mar. Sci. In press.

Stommel, H. 1963. Varieties of oceanographic experience. Science (Washington, D.C.), 139: 572-576.

Taylor, E.S. 1974. Dimensional analysis for engineers. Clarendon Press, Oxford, U.K.

Thrush, S.F., Pridmore, R.D., Bell, R.G., Cummings, V.J., Dayton, P.K., Ford, R., Grant, J., Green, M.O., Hewitt, J.E., Hines, A.H., Hume, T.M., Lawrie, S.M., Legendre, P., McArdle, B.H., Morrisey, D., Schneider, D.C., Turner, S.J., Walters, R.J., Whitlatch, R.B., and Wilkinson, M.R. 1997. The sandflat habitat: scaling from experiments to conclusions. J. Exp. Mar. Biol. Ecol. 216: 1-9.

U.S. Hydrographics Office. 1947. Atlas of surface currents, northeastern Pacific Ocean. Publ. No. 570. U.S. Hydrographics Office, Washington, D.C.

Weber, L.H., El-Sayed, S.Z., and Hampton, I. 1986. The variance 
spectra of phytoplankton, krill and water temperature in the Antarctic Ocean south of Africa. Deep-Sea Res. 33: 1327-1343.

Wilson, C., Pierce, S., Kosro, P.M., Dorn, M., and Smith, R. 1997. Ocean currents and the distribution of Pacific whiting (Merluccius productus) along the Pacific coast during summer 1995. In Changing oceans and changing fisheries: environmental data for fisheries research and management. Edited by G.W. Boehlert and J.D. Schumacher. NOAA-TM-NMFS-SWFSC No. 239.
Woodbury, D., Hollowed, A.B., and Pearce, J.A. 1995. Interannual variation in growth rates and back-calculated spawn dates of juvenile Pacific hake, Merluccius productus. In Recent developments in fish otolith research. Edited by D.H. Secor, J.M. Dean, and S.E. Campana. University of South Carolina Press, Columbia, S.C. pp. 481-497. 